\title{
O Banco Nacional de Habitação e o Programa Minha Casa Minha Vida: duas políticas habitacionais e uma mesma lógica locacional
}

\author{
The National Housing Bank and My House My Life Program: \\ two housing policies and the same locational logic
}

Marlon Lima da Silva

Helena Lúcia Zagury Tourinho

\section{Resumo}

0 artigo analisa, comparativamente, as políticas do Banco Nacional de Habitação (BNH) e do Programa Minha Casa Minha Vida (PMCMV), tendo como parâmetro a lógica locacional dos conjuntos habitacionais por elas implementados e, como recorte espacial, a Região Metropolitana de Belém (RMB). Para isso, caracteriza as duas políticas, mapeia os conjuntos habitacionais por elas implantados no contexto metropolitano, classificando-os de acordo com as três faixas de financiamento estabelecidas por cada uma dessas políticas. Mostra que, em ambos os casos, a inserção dos conjuntos habitacionais na malha urbana é determinada pelo poder de compra dos mutuários, de modo que "mora melhor" aquele que pode pagar mais pela habitação. Ao evidenciar a localização periférica dos conjuntos destinados aos estratos de menor renda destaca o nítido processo de segregação que tem marcado a produção do espaço urbano nessas políticas habitacionais.

Palavras-chave: espaço urbano; política habitacional; conjuntos habitacionais; localização; Região Metropolitana de Belém.

\begin{abstract}
This article undertakes a comparative analysis of the policies of Banco Nacional de Habitação (National Housing Bank) and Programa Minha Casa Minha Vida (My House My Life Program). Its parameter is the locational logic of the housing estates implemented by these policies in the Metropolitan Region of Belém (Northern Brazil). This paper characterizes the two policies, maps the housing estates they have set up in the metropolitan context, and classifies them according to the three funding bands laid down by each policy. It shows that, in both cases, the sites chosen for the housing estates in the urban grid are determined by the purchasing power of the borrowers, in such a way that those who "have a better home and life" are those who can pay more for the dwelling. By revealing that the housing estates targeted at those in the lowest income stratum are located on the periphery, it shows the clear segregation process that has characterized the production of urban space in these housing policies.
\end{abstract}

Keywords: urban space; housing policy; housing estates; location; Metropolitan Region of Belém. 


\section{Introdução}

A habitação constitui uma das necessidades humanas básicas, reconhecida na Declaração Universal dos Direitos Humanos e na Constituição Federal do Brasil. Diante disso, o Estado brasileiro tem viabilizado ações para a provisão de conjuntos habitacionais a diferentes segmentos, atendendo das famílias de renda mais baixa às de renda média alta. Todavia, as políticas habitacionais nacionais têm sido alvo de muitas críticas, dentre as quais são direcionadas para o atendimento insuficiente das demandas mais necessitadas e a construção de conjuntos habitacionais localizados nas periferias dos aglomerados metropolitanos, estendendo, precariamente o tecido urbano.

0 período de funcionamento do Banco Nacional de Habitação (BNH), de 1964 a 1986, concentrou parcela significativa dessas críticas (Valladares, 1989; Maricato, 2011). No entanto, cabe ressaltar que durante sua vigência, mais de 4 milhões de unidades habitacionais foram construídas, número esse que até hoje não foi superado por nenhuma outra política habitacional no país.

Em 2009, o Governo Federal lançou o Programa Minha Casa Minha Vida (PMCMV), um grande "pacote" habitacional que objetiva, dentre outras coisas, o financiamento de habitação popular. Tamanha é a densidade de recursos empregados em tão pouco tempo que é possível até mesmo comparar o PMCMV com a política desenvolvida pelo BNH. Das 3,4 miIhões de unidades habitacionais contratadas pelo PMCMV, no período 2009-2014, cerca de 1,6 milhões já foram entregues. Segundo Fix (2011), o valor inicial de 34 bilhões de reais aplicados nesse programa constituiu um fato inédito na história do país, de tal forma que nem mesmo o BNH conseguiu aplicar tantos recursos à baixa renda numa única operação. Porém, muitas das críticas tecidas ao BNH parecem reemergir no contexto do PMCMV, evidenciando contradições e conflitos que marcam a produção do espaço urbano.

Mas, até que ponto as ações do PMCMV de produção de conjuntos habitacionais, no que se refere à lógica locacional, se assemeIham ou se distinguem das empreendidas pelo extinto BNH?

0 presente trabalho tem como objetivo comparar as políticas do BNH e do PMCMV, levando em consideração a localização dos conjuntos habitacionais por elas produzidos. Utiliza-se como referência empírica de análise a Região Metropolitana de Belém, mapeando os conjuntos habitacionais segundo as diferentes faixas de financiamento estabelecidas no âmbito do BNH e do PMCMV. Ambos dividiram suas demandas em três faixas, indo das famílias de renda mais baixa às de renda média alta, possibilitando, com isso, estabelecer parâmetros de comparação quanto à localização dos conjuntos segundo os diferentes estratos.

0 trabalho se estrutura em três momentos. Inicialmente, é realizada uma breve discussão sobre habitação e espaço urbano, revelando suas interações com a política habitacional e destacando os conjuntos habitacionais como elementos relevantes na produção do espaço urbano. No segundo momento, analisa-se a estrutura basilar da produção habitacional do BNH e do PMCMV, apresentando os principais agentes envolvidos na produção e no consumo dos conjuntos habitacionais, assim como as camadas do mercado a que se destinaram. E por fim, realiza-se uma análise comparativa das 
localizações dos conjuntos habitacionais produzidos pela política do BNH e pelo PMCMV, conforme camadas de renda, na Região Metropolitana de Belém.

\section{Habitação e espaço urbano: conjuntos habitacionais em foco}

A análise comparativa das localizações dos conjuntos habitacionais do BNH e do PMCMV no interior dos aglomerados metropolitanos requer a realização de algumas considerações prévias sobre as relações entre habitação e espaço urbano.

Um simples passeio pelas grandes cidades revela, até mesmo aos observadores menos atentos, a presença de uma série de usos como, por exemplo, residencial, comercial, serviços, etc. Dentre esses, não resta dúvida de que o residencial é notadamente o uso mais presente no contexto geral, ainda que, em determinadas áreas, outros usos predominem. Isso porque, morar, assim como se alimentar e vestir, constitui uma necessidade básica dos indivíduos. Independentemente do local (na cidade pequena, média, metrópole ou no campo), ou das condições da moradia, de alguma forma é preciso morar, ainda que seja de baixo de um viaduto, num conjunto habitacional, condomínio de luxo, dentre outros (Maricato, 2009; Rodrigues, 2003).

De fato, a habitação exerce importância qualitativa e quantitativa no conjunto do ambiente construído das cidades, sobretudo, dos aglomerados metropolitanos. Sua compreensão, no entanto, requer a elucidação de alguns conceitos-chaves, dentre os quais estão os seguintes: "casa", "moradia", "habitação" e "conjuntos habitacionais".

Os termos casa, moradia e habitação, apesar de soarem aparentemente como sinônimos, apresentam certas características peculiares. De acordo com Martucci (1990), enquanto a "casa" expressa muito mais o "ente físico", ou melhor, a forma visível propriamente dita, a "moradia" se caracteriza como sendo a casa mais os "hábitos de uso da casa", ou seja, o "modo de vida dos usuários". A "habitação", por sua vez, seria conceituada como a integração da casa e da moradia ao espaço urbano.

Nessa imbricação, os conjuntos habitacionais podem ser interpretados como uma forma de habitação particular, caracterizada, de modo geral, por conter um grupo de casas, inicialmente padronizadas, de construção do tipo vertical (apartamentos) ou horizontal, oriundas ou não da ação do Estado via políticas habitacionais.

As políticas habitacionais estatais variam ao longo do tempo, destinando-se aos diferentes segmentos da demanda e materializando-se numa gama diversa de tipologias construtivas, incluindo-se nelas a de conjuntos habitacionais.

Apesar de ser um bem indispensável para a reprodução da vida, a habitação, no modo de produção capitalista, como qualquer outro bem, se converte em mercadoria que precisa ser realizada no mercado. Ocorre que apenas uma parcela pequena da demanda é solvável (Villaça, 1986), ou seja, a maioria é composta por "aqueles que não têm renda suficiente para adquirir uma determinada mercadoria e estão excluídos da demanda, não obstante dela necessitar" (Ribeiro e Pechman, 1985, p. 9). 
Nesse sentido, no mercado habitacional capitalista, "na ausência de intervenção pública, a única demanda que efetivamente se leva em conta é a demanda solvável" (Castells, 1975, p. 227). Além disso, a produção habitacional está intimamente atrelada ao solo, e este, especialmente sua localização relativa (Villaça, 2012), não pode ser reproduzido, fato que acaba encarecendo o preço final dos imóveis.

Segundo Corrêa (2007, p. 68), as práticas espaciais representam "ações espacialmente localizadas, engendradas por agentes sociais concretos, visando a objetivar seus projetos específicos". No caso da construção dos conjuntos, essas práticas se manifestam em localizações específicas, no interior das cidades.

Os agentes delimitados no âmbito das políticas habitacionais buscam diferentes subespaços no interior do aglomerado metropolitano para a construção desses conjuntos. A escolha da localização, no entanto, não ocorre de forma aleatória, há uma lógica que preside a ação. Essa lógica está relacionada com a natureza das políticas habitacionais e com os interesses dos diferentes agentes envolvidos na produção dos conjuntos. Além disso, a disponibilidade e os preços dos terrenos, também, exercem papel fundamental nas escolhas locacionais.

Conjuntos habitacionais situados em áreas bem infraestruturadas, portanto mais valorizadas, apresentam unidades habitacionais com preços mais elevados, se comparados aos conjuntos localizados em outras áreas onde o custo do fator terra é menor. Nessa lógica, restam poucas alternativas aos estratos de menor renda, como a moradia em conjuntos habitacionais periféricos (quando atendidos pelas políticas habitacionais), ou em ocupações localizadas em áreas de risco, alagadas ou em favelas. De fato, as políticas habitacionais têm atendido insatisfatoriamente a esses estratos, direcionando-se, sobretudo, para o atendimento da chamada demanda "solvável", ou seja, aqueles que podem pagar pelo alto preço da habitação.

Na busca pelas "melhores" localizações, historicamente os conjuntos habitacionais destinados aos segmentos de menor renda têm sido construídos em locais afastados da malha urbana, distantes dos setores de comércio e serviços, muitas vezes em áreas rurais, onde há disponibilidade e o preço da terra é mais baixo. Infraestrutura viária precária, insuficiência de transporte coletivo, distância significativa dos postos de trabalho e expansão desordenada do tecido urbano são apenas alguns dos problemas encontrados nessas localizações.

Assim sendo, a extensão e o esgarçamento do tecido urbano resultam de "um conjunto de forças atuando ao longo do tempo, viabilizando localizações, relocalizações e permanência de atividades e população sobre 0 espaço da cidade" (Corrêa, 2007, p. 68). A esse processo maior, adicionam-se outros, como o processo de segregação, emergindo da "capacidade que cada grupo social tem de pagar pela residência que ocupa" (Corrêa, 1989, p. 59).

Da existência da propriedade privada do solo associada à necessidade de "divisão e a parcelarização da cidade" (Carlos, 2007, p. 27), resultam que "o acesso à habitação e aos meios de consumo coletivo serão desiguais e diferenciados segundo a camada social, que se localizará e morará de modo diferenciado na cidade" (Silveira, 2003, pp. 36-37). Condicionadas por essa lógica perversa, as políticas habitacionais e a localização das suas ações 
no interior dos aglomerados metropolitanos, como a construção de conjuntos habitacionais, expressa, em última instância, os conflitos na produção do espaço urbano.

No Brasil, a "interferência do Estado, por intermédio do Banco Nacional da Habitação (BNH) ajudou a criar um modelo urbano disperso e extenso, que tende a se reproduzir" (Santos, 1994, p. 67). Esse modelo pode ser visto em várias metrópoles brasileiras, onde os exemplos mais notáveis talvez sejam os da cidade de São Paulo, com a produção do Complexo Cidade Tiradentes, "maior concentração de conjuntos habitacionais do Brasil e da América Latina" (Otero, 2009, p.16) ${ }^{1}$ e o da cidade do Rio de Janeiro, onde se implantou um grande conjunto habitacional denominado Cidade de Deus. ${ }^{2}$ Ambos foram construídos em função do deslocamento de populações atingidas por obras públicas nas áreas centrais ou próximas ao centro, marcando, grosso modo, um processo de segregação capitaneado pelo Estado.

Longe de se discutir os aspectos da expansão do tecido urbano, em diferentes metrópoles brasileiras via construção de conjuntos habitacionais, o que se ressalta é o modo como a localização desses conjuntos está intimamente relacionada a um processo maior de produção do espaço urbano, conduzido por diferentes agentes e suas respectivas práticas espaciais, podendo revelar a natureza de uma série de conflitos.

A seguir, se verá que o PMCMV parece trilhar o mesmo caminho do BNH, com semeIhanças que se traduzem na extensão do tecido urbano e na localização diferenciada dos conjuntos habitacionais, variando de acordo com as faixas de rendimento das demandas.

\section{Notas sobre a estrutura de funcionamento do Banco Nacional de Habitação e do Programa Minha Casa Minha Vida}

As semelhanças entre o BNH e PMCMV iniciam na própria estrutura de classificação das demandas, delimitando três faixas de rendimento familiar mensal. 0 Quadro 1 apresenta a segmentação da demanda e os respectivos agentes financiadores para cada estrato, no período do BNH. 


\section{Quadro 1 - Banco Nacional de Habitação Faixas de cobertura e agentes}

\begin{tabular}{|c|c|}
\hline Faixas atendidas & Agentes \\
\hline $\begin{array}{l}\text { FAIXA 1: Mercado Popular (baixa renda). } \\
\text { Caracterizado pelas famílias com renda mensal de até } \\
\text { três salários mínimos, limite posteriormente ampliado } \\
\text { para cinco salários mínimos. }\end{array}$ & $\begin{array}{l}\text { Companhias Estaduais e Municipais de Habitação } \\
\text { (COHABs). }\end{array}$ \\
\hline $\begin{array}{l}\text { FAIXA 2: Mercado econômico (renda média inferior) } \\
\text { Caracterizado pelas famílias com renda mensal entre } \\
\text { três e seis salários mínimos. }\end{array}$ & $\begin{array}{l}\text { Cooperativas habitacionais, institutos de previdência } \\
\text { social, caixas hipotecárias de clubes militares, agentes } \\
\text { de mercado de hipotecas e empresas. }\end{array}$ \\
\hline $\begin{array}{l}\text { FAIXA 3: Mercado médio (renda média superior) } \\
\text { Caracterizado pelas famílias com renda mensal } \\
\text { mínima de seis salários mínimos. }\end{array}$ & $\begin{array}{l}\text { Sistema Brasileiro de Poupança e Empréstimo (SBPE), } \\
\text { composto por: Sociedades de Crédito Imobiliário (SCIs); } \\
\text { Associações de Poupanças e Empréstimo (APEs); e } \\
\text { Caixas Econômicas. }\end{array}$ \\
\hline
\end{tabular}

Fonte: Azevedo e Andrade (1982); IDESP (1990). Elaborado pelos autores.

Além da segmentação da demanda, ressalta-se que a compreensão geral dos procedimentos para a promoção de um determinado conjunto habitacional pelo BNH constitui peça-chave à análise da produção do espaço urbano, levando em consideração a lógica de atuação dos diferentes agentes envolvidos. Nesse sentido, é válido delimitar a forma como se desenvolveu a política do BNH e destacar os principais agentes que atuaram na área de estudo, o que se encontra sintetizado no Quadro 2.

Quanto ao PMCMV, a estrutura de segmentação da demanda se assemelha à do $\mathrm{BNH}$, sendo, também, classificada em três faixas, segundo o rendimento familiar mensal. Os agentes atuantes no PMCMV, assim como suas estruturas de operação, da mesma forma que no
BNH, podem ser analisados com base nos segmentos de mercado, só que, agora, distribuídos em dois grupos, o dos que atendem a Faixa 1, de 0 a 3 salários mínimos, e os dos que atendem as faixas 2 e 3, ou seja, de 3 até 10 salários mínimos, conforme expressa o Quadro 3.

Longe de analisar em detalhes a estrutura de operação do BNH e do PMCMV, o mais importante, para fins deste trabalho, é a possibilidade de comparação das localizações dos empreendimentos resultantes dessas operações, considerando, sobretudo, as ações (práticas espaciais) dos diferentes agentes responsáveis pela produção dos conjuntos, as quais expressam os elementos conflituosos a marcar a produção do espaço urbano, como se contatará no estudo de caso da Região Metropolitana de Belém (RMB). 


\section{Quadro 2 - Banco Nacional de Habitação Principais agentes e formas de atuação}

\begin{tabular}{|c|l|}
\hline Agentes & \multicolumn{1}{c|}{ Forma de atuação } \\
\hline Cohab & $\begin{array}{l}\text { Embora Ihes fossem facultado construir diretamente, as COHABs operavam, sobretudo, através do repasse } \\
\text { de recursos do BNH para as empreiteiras e da posterior comercialização das habitações construídas entre } \\
\text { a população de renda baixa. Assim, a construção das residências era realizada por empresas privadas } \\
\text { vencedoras das licitações públicas, abertas para cada projeto individualmente. As COHABs, contudo, eram } \\
\text { incumbidas da fiscalização das obras e da liberação das parcelas do financiamento, de acordo com o } \\
\text { andamento dos trabalhos. A margem de lucro unitário das construtoras era, geralmente, menor do que na } \\
\text { maioria dos empreendimentos imobiliários e os ganhos de comercialização auferidos pelas COHABs eram } \\
\text { praticamente nulos. As Companhias se sustentavam por meio da cobrança de taxas por serviços técnicos e } \\
\text { de fiscalização. }\end{array}$ \\
\hline Ipasep & $\begin{array}{l}\text { A demanda atendida pelo IPASEP correspondia aos seus assegurados, ou seja, aos servidores estaduais } \\
\text { do Pará. A maior parte dos recursos para construção habitacional advinha do SFH (69,26\%), atendendo a } \\
\text { faixa do "mercado econômico", o restante foi constituído de recursos próprios. O IPASEP atuou também em } \\
\text { convênio com a CEF, construindo o conjunto residencial "Prefeito Stélio Maroja", em Ananindeua. }\end{array}$ \\
\hline SBPE (Socilar, & $\begin{array}{l}\text { O iniciador [empresário] deveria apresentar o projeto a ser financiado, contendo detalhado estudo de } \\
\text { viabilidade técnica e financeira junto ao BNH. Este, se satisfeitas as condições de financiamento, assinava } \\
\text { uma "Promessa de Compra e Venda de Hipotecas", através da qual assegurava ao empresário a compra dos } \\
\text { créditos hipotecários gerados com a venda do imóvel. Com a Promessa de Compra e Venda de Hipotecas, } \\
\text { o iniciador levantava junto aos agentes do SBPE (SCls, APEs e Caixas Econômicas) os recursos necessários } \\
\text { à construção. O financiador, por seu turno, refinanciava os recursos por ele concedidos ao iniciador junto } \\
\text { ao próprio BNH. Construído o imóvel e vendidas as unidades, o iniciador liquidava seu débito junto ao } \\
\text { financiador e este, por sua vez, junto ao BNH, que se transformava em detentor dos créditos hipotecários. }\end{array}$ \\
\hline
\end{tabular}

Fonte: Azevedo e Andrade (1982); IDESP (1990). Elaborado pelos autores.

\section{Quadro 3 - Programa Minha Casa Minha Vida Faixas de cobertura, agentes e formas de atuação}

\begin{tabular}{|c|c|}
\hline Faixas atendidas & Agentes e atuações \\
\hline $\begin{array}{l}\text { FAIXA 1: } 0 \text { a } 3 \text { Salários Mínimos } \\
\text { Execução via Fundo de } \\
\text { Arrendamento Residencial (FAR) }\end{array}$ & $\begin{array}{l}\text { A produção é "por oferta", o que significa que a construtora define o terreno e o projeto, } \\
\text { aprova-o junto aos órgãos competentes e vende integralmente o que produzir para a CEF, } \\
\text { sem gastos de incorporação imobiliária e comercialização, e sem risco de inadimplência } \\
\text { dos compradores ou vacância das unidades. A CEF define o acesso às unidades a partir } \\
\text { de listas de demanda, elaboradas pelas prefeituras. Os municípios têm como incumbência } \\
\text { cadastrar as famílias com rendimento de } 0 \text { a } 3 \text { salários mínimos, além da participação } \\
\text { por meio da doação de terrenos, isenção tributária e desburocratização nos processos } \\
\text { de aprovação e licenciamento e também na flexibilização das normas urbanísticas para } \\
\text { permitir aumentar os índices de utilização do solo nos empreendimentos do PMCMV. }\end{array}$ \\
\hline $\begin{array}{l}\text { FAIXA 2: de } 3 \text { a } 6 \text { Salários Mínimos } \\
\text { Financiamento via Fundo de Garantia } \\
\text { por Tempo de Serviço (FGTS) }\end{array}$ & \multirow{2}{*}{$\begin{array}{l}\text { As construtoras/ incorporadoras apresentam projetos de empreendimentos à CEF, que } \\
\text { realiza pré-avaliação e autoriza o lançamento e comercialização. Após a conclusão da } \\
\text { análise e comprovação da comercialização mínima exigida, é assinado o Contrato de } \\
\text { Financiamento à Produção. A comercialização é feita pelas construtoras ou através } \\
\text { dos "feirões" da Caixa, havendo a possibilidade de que os pretendentes à aquisição } \\
\text { consigam uma carta de crédito na Caixa para ir ao mercado buscar uma moradia para } \\
\text { aquisição. }\end{array}$} \\
\hline $\begin{array}{l}\text { FAIXA 3: de } 6 \text { a } 10 \text { Salários Mínimos } \\
\text { Financiamento via Fundo de Garantia } \\
\text { por Tempo de Serviço (FGTS) }\end{array}$ & \\
\hline
\end{tabular}

Fonte: Cardoso e Lago (2013). Adaptado pelos autores. 


\section{Experiências do Banco Nacional de Habitação e do Programa Minha Casa Minha Vida na Região Metropolitana de Belém}

A Região Metropolitana de Belém (RMB) é composta, atualmente, pelos municípios de Belém, Ananindeua, Marituba, Benevides, Santa Bárbara do Pará, Santa Isabel do Pará e Castanhal (Figura 1).

Para a análise comparativa das localizações dos conjuntos habitacionais do BNH e do PMCMV é válido partir de uma breve caracterização da estruturação atual da RMB. Conforme a Figura 2, a mancha urbana contínua adensada encontra-se no núcleo metropolitano de Belém, em Ananindeua e Marituba, ocorrendo de forma descontínua nos demais municípios. Mais afastado do núcleo metropolitano está a vasta área urbana de Castanhal, município integrado mais recentemente (2013) à RMB.

Sua principal aglomeração de comércio e serviços está presente no interior da chamada Primeira Légua Patrimonial de Belém - área de uma légua concedida por meio de Carta de Sesmaria à municipalidade no século XVII, iniciando oficialmente o patrimônio municipal de Belém (Sarges, 2002).

A malha urbana se desenvolveu a partir da nucleação inicial, localizada na confluência da baía do Guajará com o Rio Guamá, avançando na direção de outros municípios (Figura 3), a maioria deles originada a partir da instalação de estações localizadas às margens da Ferrovia Belém-Bragança ou de rodovias implantadas, sobretudo, a partir da década de 1960.

Figura 1 - Região Metropolitana de Belém Composição municipal

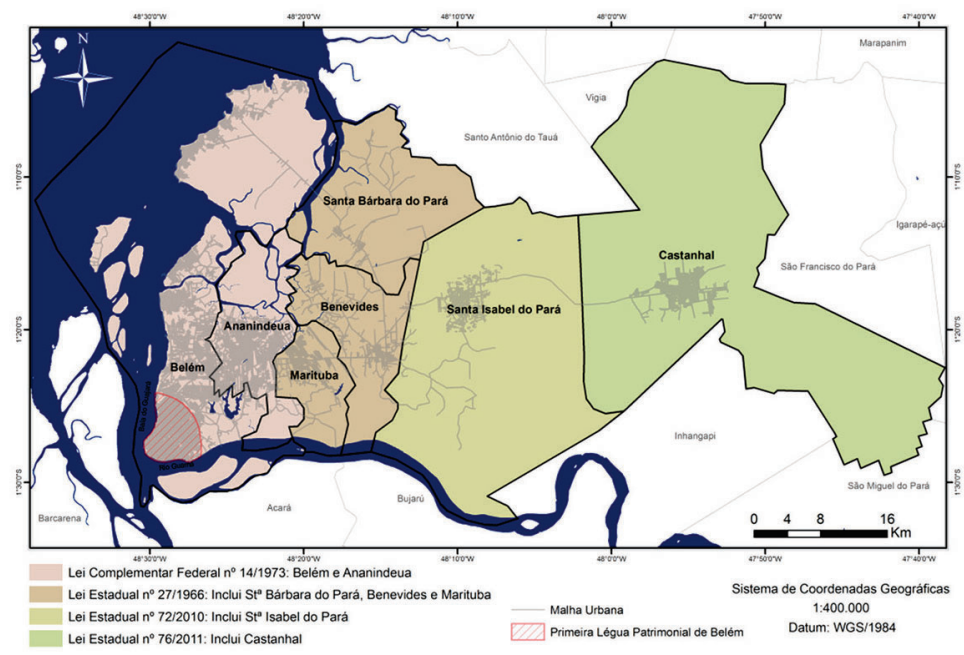

Elaboraç̧ão: Autores. 
Figura 2 - Região Metropolitana de Belém Áreas rurais e urbanas, 2010

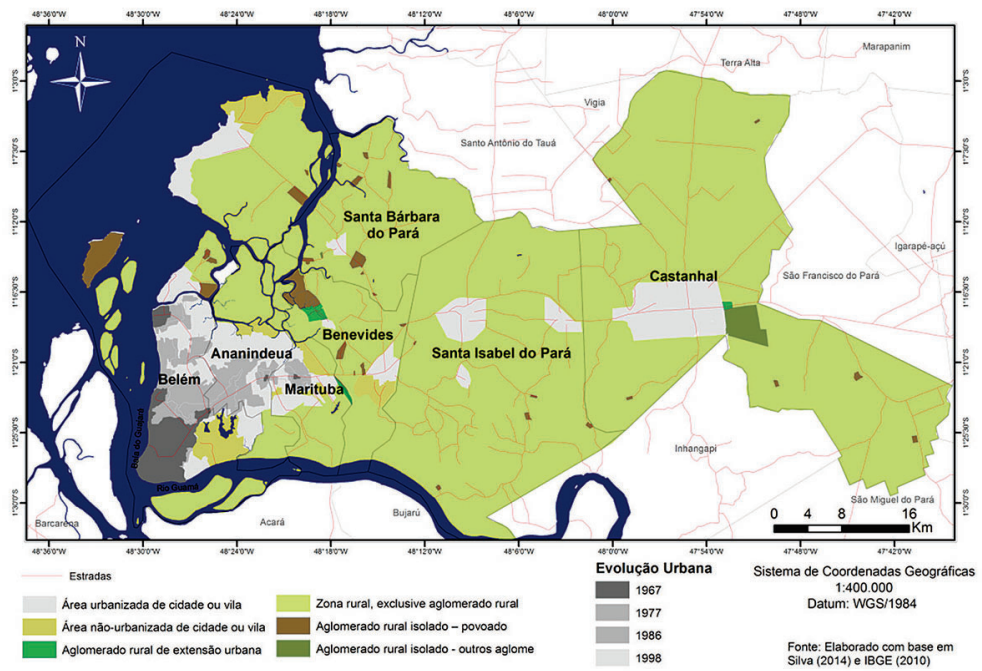

Elaboração: Autores.

Figura 3 - Região Metropolitana de Belém

Processo de conurbação, 1967-1977-1986

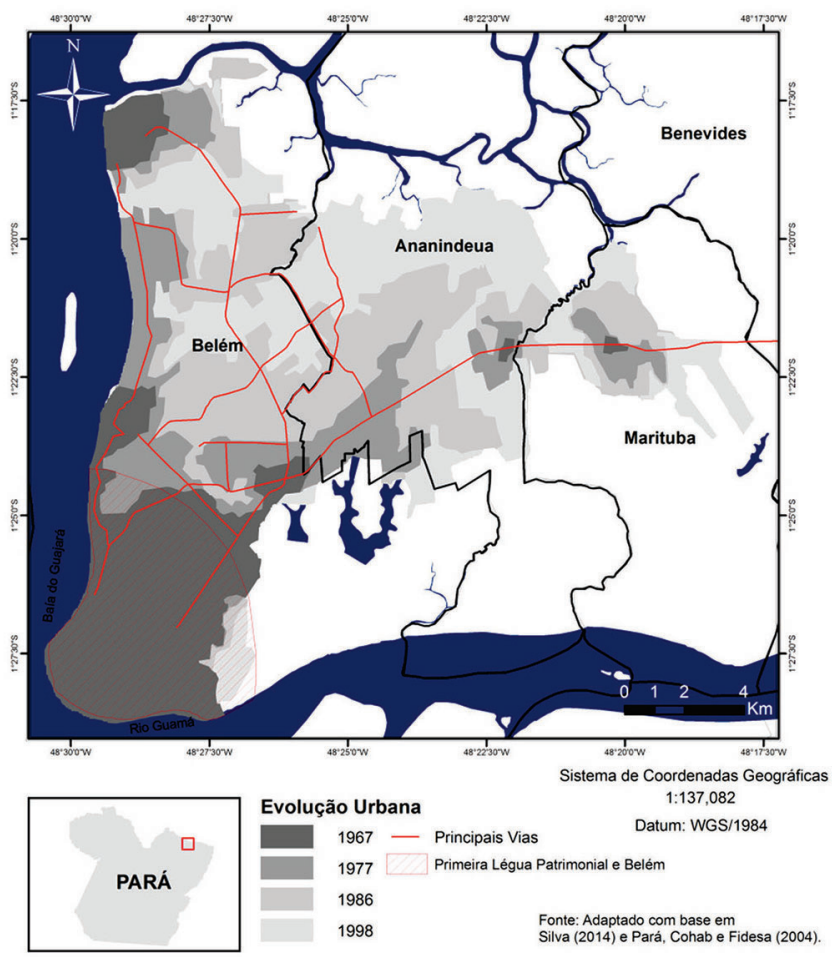

Elaboraç̧ão: Autores. 
Para o espraiamento da malha urbana, intensificado a partir de fins dos anos 1970, colaborou a produção de conjuntos habitacionais, frutos da política do BNH. Ao exemplo do que ocorreu na grande maioria das cidades brasileiras, a localização destes empreendimentos tem se dado principalmente em áreas periféricas, 0 que contribuiu, num primeiro momento, para a ocupação após a Primeira Légua Patrimonial, no município de Belém, e, posteriormente, para a conurbação de Belém com outros municípios da região metropolitana. Ressalte-se que, a partir da década de 1960, a mancha urbana vem se expandindo de forma acelerada, não apenas em função da construção de conjuntos habitacionais, mas, também, de outras tipologias de habitação, tais como as ocupações irregulares e os condomínios fechados, primeiros os horizontais voltados para camadas de maior renda e, mais recentemente, condomínios verticais destinados, principalmente, aos estratos médios de renda (Figuras 4 e 5).

A Figura 6 acrescenta, ao mapa de evolução da malha urbana até 1998, informações das localizações dos conjuntos habitacionais financiados pelo BNH por faixa de mercado. Destaque-se que a área conurbada da RMB ao final dos anos 1990 era composta pelos municípios de Belém, Ananindeua e Marituba. Da sua análise fica evidente que a política do BNH, com a construção de grandes conjuntos habitacionais na periferia dos núcleos urbanos, contribuiu significativamente para o processo de conurbação, assim como para a extensão da mancha urbana sobre áreas consideradas rurais.

Figura 4 - Região Metropolitana de Belém

Conjuntos habitacionais em 1982 e em 1989

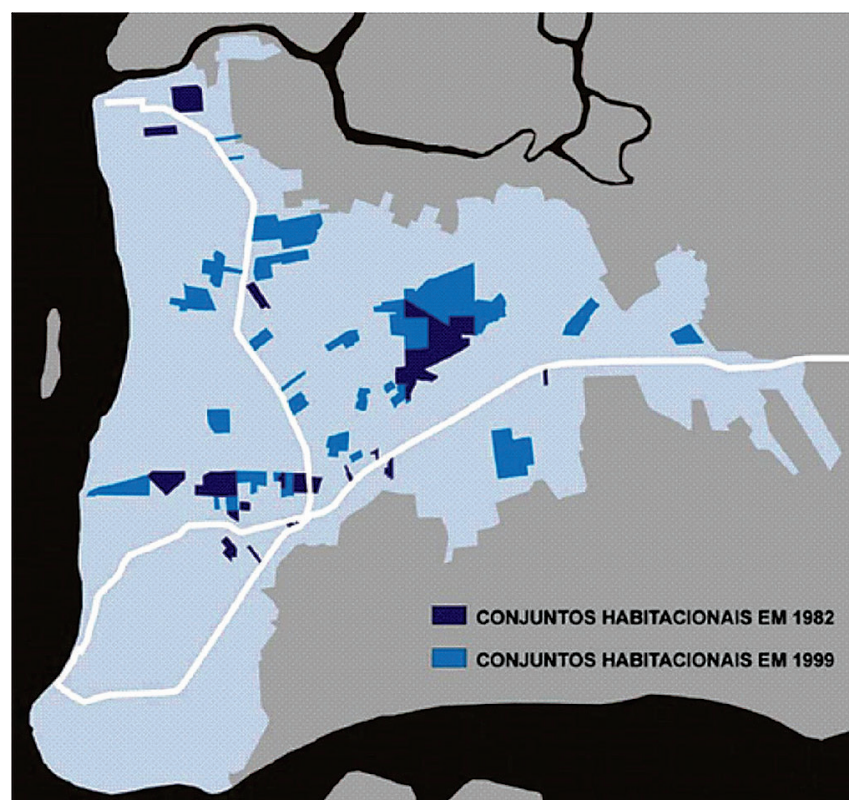

Fonte: Ampla Terra, Jica e Sedurb (2003). 
Figura 5 - Região Metropolitana de Belém Áreas ocupadas irregularmente, 1999

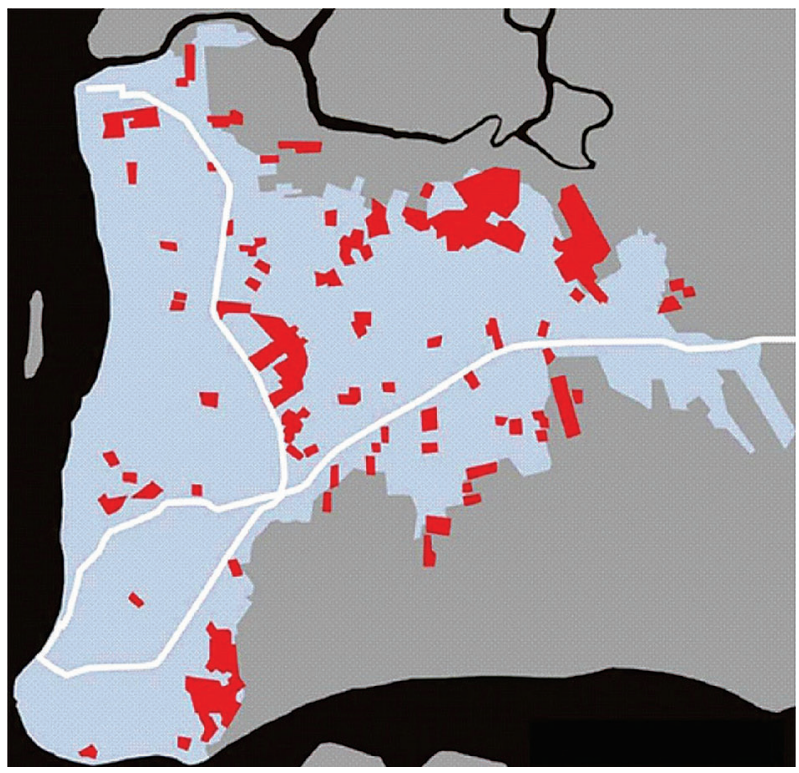

Fonte: Ampla Terra, Jica e Sedurb (2003).

Figura 6 - Região Metropolitana de Belém - Conjuntos habitacionais do Banco Nacional de Habitação, segundo faixa de atendimento ${ }^{3}$

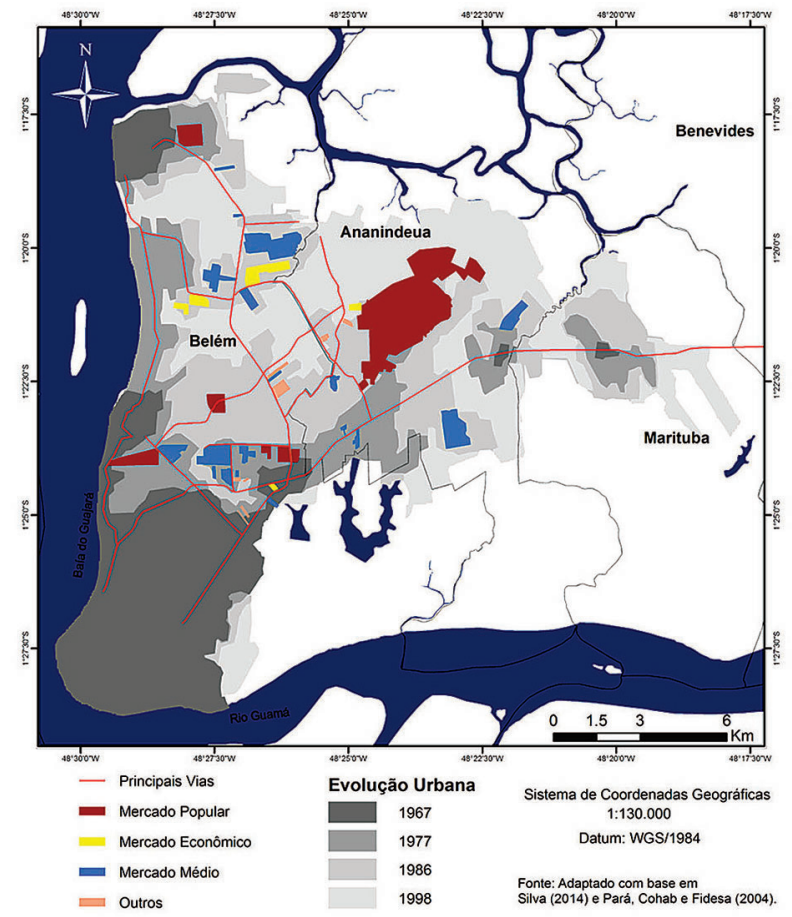

Elaboração: Autores. 
Essas ações, além de atraírem ocupações irregulares, como indicadas na Figura 5, favoreceram a valorização de vastas áreas "vazias", localizadas entre os conjuntos habitacionais e nos interstícios desses com as principais vias de circulação metropolitana. Eixos como os da Rodovia Augusto Montenegro e da Avenida Mário Covas se valorizaram a cada novo lançamento habitacional - o que de certa forma inviabilizou, no segundo momento, a produção para o mercado popular e sinalizou possibilidades para atuação dos mercados econômico e médio - além de proporcionarem sobrelucros para os proprietários fundiários na tendência de auferirem as diferentes rendas da terra.

Atente-se para a concentração dos conjuntos em Belém e Ananindeua, ficando uma vasta área, sem a presença de nenhum conjunto habitacional. Não se pode perder de vista, nesse contexto, que, até o início da década de 1990, a RMB era composta apenas por Belém e Ananindeua, e a política do BNH priorizou as regiões metropolitanas que foram institucionalizadas em 1973, já que nelas estava a presença dos maiores contingentes populacionais.

Além dos municípios conurbados de Belém e Ananindeua, apenas o de Castanhal recebeu conjuntos habitacionais financiados pelo $\mathrm{BNH}$, sendo esses voltados para o mercado popular e determinados muito mais pela dinâmica urbana própria do município do que por uma dinâmica metropolitana.

0 padrão locacional da política do $\mathrm{BNH}$ na RMB pode ser percebido, também, ao se cruzar as informações da hierarquia viária com a da localização dos conjuntos habitacionais, classificados segundo a faixa de financiamento. Quanto maior o nível hierárquico da via, ou seja, a acessibilidade, maior o nível de renda para o qual o conjunto foi destinado, o que mostra a intensa relação existente entre valor da terra e acessibilidade.

Diante dessas informações pode-se inferir que os mercados econômico e médio se materializaram distintamente do mercado popular na RMB. As áreas localizadas no entorno da Primeira Légua Patrimonial foram preenchidas massivamente pelo mercado médio que aproveitou a proximidade com a principal centralidade de comércio e serviços para agregar valor na comercialização de seus empreendimentos, destinados a uma faixa de renda superior, capaz de pagar pelo alto preço da habitação. Com o esgotamento dessas áreas, no final da década de 1970, e a possibilidade de aquisição de novos terrenos em áreas que se valorizavam com as edificações do mercado popular, o mercado médio passou a atuar, também, em outros setores, dissipando-se ao longo das principais vias em Belém e Ananindeua.

Já as áreas mais afastadas do centro e das vias mais importantes foram apropriadas pelo mercado popular. A atuação desse mercado, desde o início da política do BNH, caracterizou-se, de um modo geral, pelo uso de terrenos doados, localizados em grandes áreas rurais, estendendo precariamente o tecido urbano e deixando grandes "vazios" que, paulatinamente, foram apropriados pelo mercado médio, como já foi ressaltado. Dentre os grandes conjuntos habitacionais construídos, destaca-se 0 complexo Cidade Nova, em Ananindeua, que contém 13.903 unidades habitacionais (Idesp, 1990), sendo até hoje o maior conjunto habitacional da RMB.

A Figura 7 apresenta os conjuntos habitacionais materializados pelo PMCMV na RMB, segundo as três faixas de financiamento. 
Figura 7 - Região Metropolitana de Belém - Conjuntos habitacionais do Programa Minha Casa Minha Vida, segundo faixa de atendimento

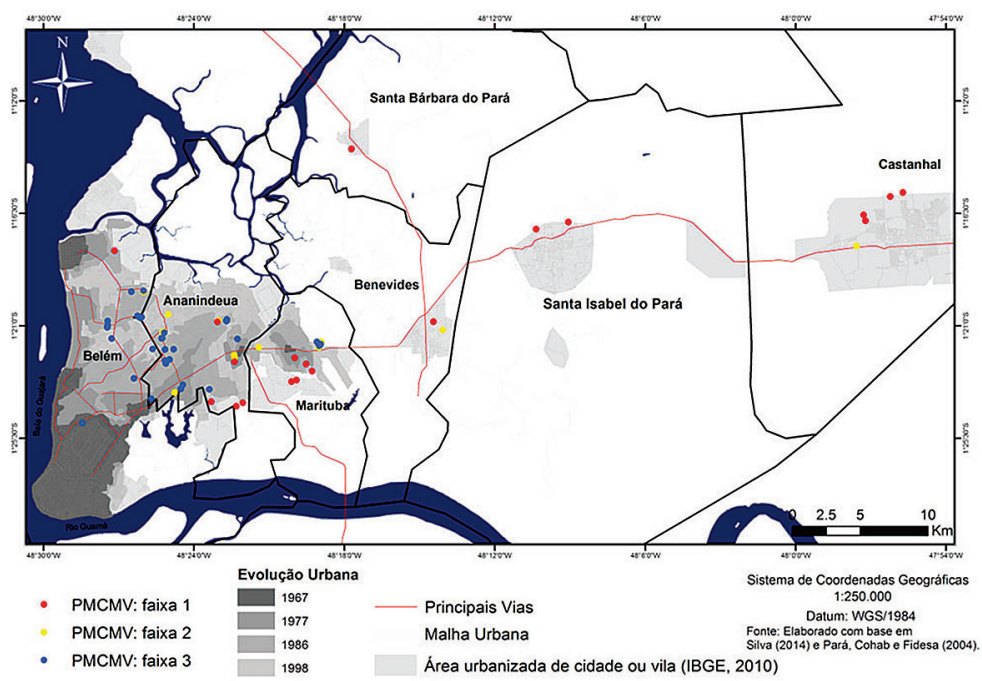

Elaboração: Autores.

Diferentemente do que ocorreu com o BHN, o PMCMV esteve presente em todos os municípios que hoje integram a RMB, sendo o principal mercado responsável por este feito a construção de conjuntos habitacionais destinados à Faixa 1, o que, a princípio, faz crer que este Programa teria rompido com a lógica locacional vigente anteriormente. Todavia, comparar o PMCMV com BNH, considerando somente o alcance municipal das ações, não conduz a análises mais substanciais sobre a forma como tem sido incorporada a produção habitacional destinada às deferentes faixas de financiamento na RMB.

A dispersão espacial dos conjuntos habitacionais da Faixa 1 do PMCMV em muito se deve ao fato de as áreas "disponíveis" para a produção popular, próximas da centralidade principal de comércio e serviços e de melhor acessibilidade, estarem cada vez mais escassas e caras, sobretudo em Belém e Ananindeua, o que tem forçado as construtoras a se direcionarem para setores mais afastados, alcançando locais em que o BNH não havia atuado até então. Tais áreas têm sido encontradas, quer na periferia mais distante de Ananindeua e Marituba, quer em outros municípios metropolitanos. Colabora para isso, certamente, a não implementação dos instrumentos do Estatuto da Cidade de combate à retenção de lotes vazios ou subutilizados e à especulação imobiliária. 
Por um lado, as áreas que foram valorizadas paulatinamente com as ações do $\mathrm{BNH}$, e que hoje se encontram incorporadas ao tecido urbano, têm sido apropriadas por empreendimentos da Faixa 3 do PMCMV, ou seja, são destinadas aos estratos que podem pagar pelas melhores localizações em relação ao centro metropolitano e condições de acessibilidade.

Diante desse cenário, nota-se que os padrões locacionais dos conjuntos habitacionais, no âmbito do PMCMV, têm seguido a mesma lógica verificada anteriormente, na época do BNH, marcada pela localização dos conjuntos destinados às faixas de mercado de menor renda nas áreas mais distantes da centralidade principal metropolitana e de menor acessibilidade viária, revelando que as contradições e os conflitos que se expressavam na produção do espaço urbano do BNH permanecem os mesmos. Com isso, fica evidente, mais uma vez, a dificuldade em prover habitações bem localizadas para a Faixa 1 na RMB.

\section{Considerações finais}

0 trabalho analisou e comparou a política do Banco Nacional de Habitação (BNH) e o Programa Minha Casa Minha Vida (PMCV), tendo como parâmetro a localização dos conjuntos habitacionais na Região Metropolitana de Belém (RMB).

Considerando as semelhanças quanto à estrutura de atendimento das demandas, foi possível comparar o padrão locacional dos conjuntos habitacionais implantados no período BNH com as dos conjuntos que vêm sendo construídos por meio do PMCMV. Nesse sentido, a divisão em três faixas de financiamento, de acordo com o rendimento familiar mensal dos estratos atendidos, possibilitou 0 mapeamento e a classificação dos conjuntos habitacionais no contexto metropolitano, constituindo parâmetro norteador de análises.

Observou-se que os conjuntos habitacionais se localizam distintamente em setores específicos na RMB, variando segundo as faixas de atendimento, numa lógica que revela o movimento conflituoso da produção do espaço urbano. Foi constatado que as acessibilidades, no tocante à localização dos conjuntos, são diretamente proporcionais ao poder de compra dos mutuários, configurando um cenário que se faz presente tanto no $\mathrm{BNH}$, quanto no PMCMV.

Enquanto os conjuntos destinados aos segmentos de menor renda têm se concentrado em áreas mais periféricas, ou até mesmo rurais, ocupando precariamente essas áreas, os conjuntos destinados às faixas superiores têm sido construídos em subespaços mais integrados à mancha urbana, ao longo das principais vias de circulação. Essa segmentação dos locais de moradia, entre os que podem e os que não podem pagar mais pela habitação e pelas melhores localizações, tem se repetido ao longo das políticas habitacionais, desenhando um processo nítido de segregação. Em última instância se fundamenta no problema do acesso à terra para implantação de empreendimentos habitacionais voltados às camadas inferiores de renda, entrave que nem a política do $\mathrm{BNH}$, nem a do PMCMV têm enfrentado de maneira efetiva.

Contraditoriamente, a materialização dessas políticas tem contribuído para agravar ainda mais esse quadro. Cada novo empreendimento habitacional, mesmo situado em 
áreas afastadas, eleva o preço do solo no seu entorno, o que, de certa forma, inviabiliza a produção de novos conjuntos destinados aos segmentos de menor renda.

Não resta dúvida de que o rompimento dessa lógica perpassa pela superação de uma "barreira" estrutural, sobretudo quando se considera que o processo de produção habitacional está intimamente atrelado ao solo que, além de não poder ser reproduzido, está sujeito a uma série de fatores que encarecem seu preço como, por exemplo, a existência da propriedade privada e a não implementação efetiva dos mecanismos de combate à retenção especulativa do solo e de imóveis urbanos instituídos pelo Estatuto da Cidade.

\section{Marlon Lima da Silva}

Universidade Federal do Pará, Faculdade de Geografia e Cartografia. Belém/PA, Brasil. marlon.angelim@yahoo.com.br

\section{Helena Lúcia Zagury Tourinho}

Universidade da Amazônia, Programa de Mestrado em Desenvolvimento e Meio Ambiente Urbano. Belém/PA, Brasil.

helenazt@uol.com.br

\section{Notas}

(1) "Cidade Tiradentes abriga o maior complexo de conjuntos habitacionais da América Latina, com cerca de 40 mil unidades, a maioria delas, construídas na década de 1980 pela Cohab (Companhia Metropolitana de Habitação de São Paulo), CDHU (Companhia de Desenvolvimento Habitacional e Urbano do Estado de São Paulo) e por grandes empreiteiras, que inclusive aproveitaram o último financiamento importante do BNH (Banco Nacional da Habitação), antes de seu fechamento" (www.prefeitura.sp.gov.br)

(2) "Na década de 1960, com a transformação do Distrito Federal em Estado da Guanabara, o Governador Carlos Lacerda implementou uma política de remoção das favelas situadas na zona sul da Cidade, no entorno da Lagoa Rodrigo de Freitas, além de algumas outras, para isso autorizando a construção de grande conjunto habitacional na baixada de Jacarepaguá. Surgiu assim a Cidade de Deus. Construída pela Cohab e financiada pelo BNH". (www.portalgeo.rio. rj.gov.br).

(3) Em decorrência da indisponibilidade de dados, os conjuntos habitacionais mapeados do período BNH foram apenas aqueles localizados para além da Primeira Légua Patrimonial de Belém. 


\section{Referências}

\section{AMPLA TERRA ASSESSORIA E PLANEJAMENTO AMBIENTAL; AGÊNCIA DE COOPERAÇÃO INTERNACIONAL} DO JAPÃO (JICA); SECRETARIA EXECUTIVA DE DESENVOLVIMENTO URBANO E REGIONAL (SEDURB). (2003). Estudo de impacto ambiental do estudo de viabilidade econômica de projetos para o melhoramento do sistema de transportes da Região Metropolitana de Belém. Belém.

AZEVEDO, S. e ANDRADE, L. A. G. (1982). Habitação e poder: da Fundação da Casa Popular ao Banco Nacional de Habitação. Rio de Janeiro, Zahar.

CARDOSO, A. L. (org.) e LAGO, L. C. (2013). O Programa Minha Casa Minha Vida e seus efeitos territoriais. Rio de Janeiro, Letra Capital.

CARLOS, A. F. A. (2007). O espaço urbano: novos escritos sobre a cidade. São Paulo, Labur/Edição Eletrônica. Disponível em: http://pt.scribd.com. Acesso em: 10 jun 2013.

CASTELLS, M. (1975). A questão urbana. São Paulo, Paz e Terra.

CORRÊA, R. L. (1989). O espaço urbano. São Paulo, Ática.

(2007). Diferenciação socioespacial, escala e práticas espaciais. Cidades. Presidente Prudente, v. 4 , n. 6 , pp. 61-72.

FIX, M. A. B. (2011). Financeirização e transformações recentes no circuito imobiliário no Brasil. Tese de doutorado. Campinas, Universidade Estadual de Campinas.

IBGE - Instituto Brasileiro de Geografia e Estatística (2010). Malhas digitais: censo 2010. Disponível em: http://downloads.ibge.gov.br/downloads_geociencias.htm. Acesso em: 22 jan 2014.

IDESP - Instituto de Desenvolvimento Econômico, Social e Ambiental do Pará (1990). Avaliação das intervenções do poder público na questão habitacional no Pará. Belém.

MARICATO, E. (2009). Por um novo enfoque teórico na pesquisa sobre habitação. Cadernos Metrópole. São Paulo, v. 21, pp. 33-52. Disponível em: http://www.cadernosmetropole.net/download/cm_ artigos/cm21_147.pdf. Acesso em: 24 abr 2014.

(2011). O impasse da política urbana no Brasil. São Paulo, Vozes.

MARTUCCI, R. (1990). Projeto tecnológico para edificações habitacionais: utopia ou desafio? Tese de doutorado. São Paulo, Universidade de São Paulo.

OTERO, E. V. (2009). As possibilidades e os limites da reabilitação de conjuntos habitacionais em São Paulo. Dissertação de mestrado. São Paulo, Universidade de São Paulo. Disponível em: www. teses.usp.br/teses/disponiveis/16/.../Dissertacao_EstevamOtero.pdf. Acesso em: 15 jan 2013.

PARÁ (2004). Secretaria Executiva de Desenvolvimento Urbano e Regional; Companhia de Habitação do Estado do Pará (COHAB); Fundação para o Desenvolvimento da Amazônia (FIDESA). Região Metropolitana de Belém: estudos preliminares do plano estratégico. Relatório Parcial 3. Belém. Trabalho não publicado.

RIBEIRO, L. C. Q. e PECHMAN, R. M. (1985). O que é questão de moradia? São Paulo, Nova Cultural/ Brasiliense.

RODRIGUES, A. M. (2003). Moradia nas cidades brasileiras. São Paulo, Contexto.

SARGES, M. N. (2002). Belém: riquezas produzindo a belle-époque (1870-1912). Belém, Pakatatu. 
SANTOS, M. (1994). Técnica, espaço, tempo: globalização e meio técnico-científico-informacional. São Paulo, Hucitec.

SILVA, M. L. (2014). Habitação produzindo espaço urbano na reprodução de conjuntos habitacionais: experiências e tendências na Região Metropolitana de Belém. Dissertação de mestrado. Belém, Universidade Federal do Pará.

SILVEIRA, L. R. (2003). Cidade, corporação e periferia urbana: acumulação de capital e segregação espacial na (re) produção do espaço urbano. Santa Cruz do Sul, EDUNISC.

VALLADARES, L. P. (1993). Repensando a habitação no Brasil. Rio de Janeiro, Zahar.

VILLAÇA, F. (1986). O que todo cidadão precisa saber sobre habitação. São Paulo, Global. (2012). Reflexões sobre as cidades brasileiras. São Paulo, Nobel.

Texto recebido em 22/mar/2015

Texto aprovado em 20/jul/2015 
